\title{
Gamified Workshops as Drivers for Attitudinal and Behavioral Shifts toward Sustainable Business Practices: The Role of Enjoyment, Curiosity and External Regulation
}

\author{
Lisa-Maria Putz \\ University of Applied Sciences, Upper Austria \\ lisa-maria.putz@fh-steyr.at
}

\author{
Horst Treiblmaier \\ MODUL University Vienna \\ horst.treiblmaier@modul.ac.at
}

\begin{abstract}
Gamification has recently gained a great deal of attention in various research communities. The application of game elements in non-game contexts has shown a lot of potential and the expectations of researchers and businesses are high. However, few studies exist that empirically test the effectiveness of gamification applications in business settings. To fill this gap, we present results from workshops that promoted environmentally friendly business practices. 261 individuals participated in a study in which various gamification elements were applied. Our findings illustrate that enjoyment and curiosity, both of which are strongly fostered by gamification elements, exert a significant influence on individuals' attitudes and subsequently their behavioral intentions to adopt sustainable business practices. In contrast, the impact of external regulation turned out to be insignificant. The findings highlight the important role of enjoyment and curiosity for a sustainable change and bear important implications for academics and practitioners.
\end{abstract}

\section{Introduction}

Alarmed by the climate crisis as well as other negative environmental and societal impacts of industrialization on sustainability [29], various stakeholder groups exert substantial pressure on managers to adopt more sustainable business practices. Sustainability has thus become a crucial factor in management practice [18, 60] and IS researchers are considering strategies to actively create a positive impact [22]. Especially the crossdisciplinary field of Supply Chain Management (SCM) bears a lot of potential for pursuing sustainability goals. According to [60] "the need for environmental protection and increasing demands for natural resources are forcing firms to reconsider their business models and restructure their supply chain operations" (p. 577).

Transport is the single research area within SCM that has the most significant environmental impact [17]. In 2014, the transport sector alone accounted for $23 \%$ of global $\mathrm{CO}_{2}$ emissions and for $15 \%$ of overall greenhouse gas emissions [34]. Forecasts indicate that freight volume will quadruple by 2050 [48], which is expected to lead to further substantial increases of greenhouse gas emissions. A change in SCM professionals' attitudes and behaviors is therefore needed to incorporate sustainable transport modes such as railway and inland waterway transport in their supply chains and to enhance sustainable business practices. Today, in many companies an insufficient understanding exists about the potential benefits of sustainable governance [51].

Gamification, which can be defined as "the use of game elements in non-game settings" [15], is frequently used to motivate individuals to develop (new) skills and to change their behavior [33, 57]. In recent years, the application of gamification has become increasingly popular, with games or game elements being included in individuals' daily activities [41]. Gamification is used in fields as diverse as sports, health, sustainability, education, marketing, and business in order to address motivation and influence individuals' behaviors [6, 15]. [59] provided a framework on how gamification can be used for supply chain management education in order to increase students' level of engagement and enjoyment of the courses. [16] conducted a study in an operations research class and found that the percentage of successful students and students' participation in class increased. According to [30], individual's behavior and attitude toward environmental consciousness can be influenced by gamification. However, there is a dearth of empirical literature investigating gamified information systems in a business context and measuring their impact on individuals' attitudes and behaviors [42]. 
In this paper, we take one step to help to close this research gap and investigate the potential of gamification to impact attitudes and behaviors of aspiring SCM professionals. To ensure the comparability of the results, we follow the suggestions of [27] on how to design proper gamification studies. The goal of this paper is to examine the effects of enjoyment, curiosity and external regulation on attitude and behavioral intention within the context of sustainable supply chains. We target young business professionals from the transport industry in their role as future decision makers and use gamified workshops to trigger the desired changes. A quantitative survey in combination with structural equation modeling (SEM) is used to investigate the relationships between the constructs in the proposed research model.

In the following sections we first introduce the concept of gamification and identify relevant game elements [36]. Next, we discuss the theoretical background, the hypotheses and the research model. Then, we present and analyze the results of the model and, finally, we discuss potential implications for both researchers and practitioners as well as ideas for future research.

\section{Literature review}

To create and maintain sustainable supply chains, a change in SCM managers' attitudes and behaviors is needed. The academic literature offers a multitude of potential attitudinal and behavioral antecedents, with many scholarly papers highlighting the importance of individuals' motivation to ensure longlasting change. Such a change can be achieved, for example, by applying various game elements [24].

\subsection{Gamification to change attitude and behavior}

In 1938, Huizinga claimed that individuals enhance their capabilities and knowledge by the process of playing and named his theory "homo ludens", which literally translates into "playing man" [31]. His key message is that humans learn through playing and that play is one of their main inner drivers. He focuses on the intrinsic motivation of free playing without a specific aim. Similarly, gamification builds on an individual's instinct to play. This desire can be used to change attitudes and to achieve a desired behavioral change. Previous research on gamification can be separated into psychological (e.g., attitude, enjoyment) and behavioral consequences (e.g., intention to use), with most research so far being focused on behavioral outcomes [27]. Users have been shown to change behavior (e.g., increased participation) when applications are enriched with gamification elements $[6,24]$. [52] demonstrated that an increase in motivation, which can be achieved through gamification, leads to improved performance. Using data of users of an online gamified exercise service, [26] found that enjoyment was directly and positively associated with continued use and that playfulness had an indirect effect. [39] used a gamified application to foster sustainable communities and concluded that "gamification principles are congruent with needed changes to educating individuals about sustainability issues" (p. 1498). Gamification has also been successfully used to support behavioral changes pertaining to the responsible use of electricity [28]. Since attitude is an important antecedent of behavioral intention [5], all attitudinal changes strongly influence subsequent behavior.

\subsection{Enjoyment, curiosity and external regulation}

The use of hedonically motivated information systems to boost productivity or to create value has recently received attention in IS research [43, 49]. In a hedonic environment, intrinsic motivation drives individuals' behavior, since they use a system or an application for intrinsic rewards such as enjoyment or pleasure instead of external rewards such as monetary gains [43]. Moreover, intrinsic motivation has been previously shown to be a strong predictor for the intention to use a hedonic information system $[9,54]$.

Enjoyment is an example of an intrinsic motivator [43] and describes an individual's perception of how entertaining, pleasurable, and fun a specific activity is [54]. Since games are intrinsically motivating, they can be seen as hedonic systems that people play for their own sake [41, 44]. Gamification refers to the process of enhancing services with game elements to increase value for participants [33] by combining both hedonic and utilitarian elements [25, 49]. Accordingly, [25] (p. 134) describe gamification as "where the goals of the systems' use are related to productivity, although the means and the design by which the systems promote productivity are hedonic in nature. Utilitarian games can hence be characterized as 'productivity through fun'." Enjoyment can thus be considered as an outcome of the process of flow [9, 46]: an innately positive experience, which is closely connected to feelings of enjoyment. Flow theory describes this state as an 
individual's complete absorption and its manifold consequences [10].

Curiosity represents another element of intrinsic motivation [44]. It can be defined as "a positive emotional-motivational system associated with the recognition, pursuit, and self-regulation of novel and challenging opportunities" [37] (p. 291). Curiosity can thus be explained as a motivational state that increases engagement and leads to exploratory behavior. Therefore, enjoyment is not necessarily a prerequisite for curiosity [4], but both constructs have been shown to impact motivation $[37,43]$ as well as innovation adaption [45] and can be considered as intrinsic factors. Gamification aims to increase individuals' curiosity by enriching service, educational or work activities with game elements [25] [36], for example, by designing appealing game environments or by creating challenging tasks [36].

Both enjoyment and curiosity have the potential to increase intrinsic motivation. In order to also account for mandated use [56], we have included the construct "external regulation", which refers to behavior that is regulated through external means. Although the motives for such behaviors might be different, obliging individuals to carry out specific activities is typical of most working environments. In an IS context, external regulation has previously been shown to exert a significant influence on subjective norm [8] and to positively influence the extent of open source software adoption [40].

\section{Research hypotheses}

A huge amount of IS literature exists that postulates a significant impact of enjoyment (or closely related constructs such as joy and playfulness) on individuals' attitudes and behavioral intentions [54][43]. Previous research has modeled attitude as a mediating variable between individual beliefs or evaluations and behavioral intention [13]. Accordingly, we model attitude as a mediator between enjoyment and behavioral intention, and hypothesize:

H1: Enjoyment positively influences individuals' attitudes toward sustainable transport

[32] initially modeled curiosity (together with enjoyment and concentration) as a reflective subdimension of attitude and subsequently in a decomposed structural model as a direct antecedent of attitude. Their results in a context of social networking sites show that in both cases a significant effect exists. Similarly, [38] modeled curiosity as a sub-dimension of cognitive engagement and found a significant effect on attitude in their study about learner acceptance of a multimedia-based learning system. Thus we hypothesize a positive effect of curiosity on attitude:

H2: Curiosity positively influences individuals, attitudes toward sustainable transport

By definition, gamification appeals to individuals' inner urge to engage in activities that are playful. The IS community has previously differentiated between mandated and discretionary use [21]. Previous results on mandated use of technology differ, and [7], who tested a TAM model in the banking industry, concluded that their model "also does not fare well when usage is mandated" (p. 290). Given the somewhat contradictory notions of play and mandated use, we hypothesize:

H3: External regulation negatively influences individuals' attitudes toward sustainable transport

The positive link between attitude and behavioral intention has been postulated and tested numerous times as a part of theories such as the Theory of Reasoned Action [20], Theory of Planned Behavior [2] and the TAM [12]. This relationship has been confirmed through numerous empirical studies, independent of the underlying theory and the research design. Accordingly, we hypothesize:

H4: Individuals' attitudes toward sustainable transport positively influence their intention to use them

Figure 1 summarizes our hypotheses in a comprehensive yet parsimonious model that includes two intrinsic factors closely related to the playfulness of gamification (i.e., enjoyment, curiosity) as well as one construct representing mandated use (i.e., external regulation).

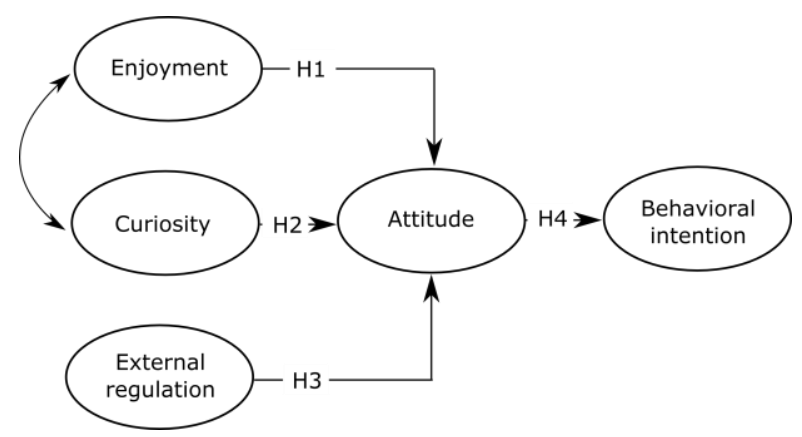

Figure 1. Research model 
Furthermore, our research model exhibits a correlation between enjoyment and curiosity, which is based on logical considerations [3] as well as previous research findings [35]. Both constructs measure intrinsic phenomena and we therefore assume a strong correlation between them. Table 1 summarizes the model constructs and provides definitions as well as sources from the academic literature.

Table 1. Research model constructs and sources

\begin{tabular}{|c|c|c|}
\hline Construct & Definition & Source \\
\hline Enjoyment & $\begin{array}{l}\text { The pleasurable aspects of the } \\
\text { interaction described as being fun } \\
\text { and enjoyable rather than boring }\end{array}$ & [1], p. 673 \\
\hline Curiosity & $\begin{array}{l}\text { The extent the experience arouses } \\
\text { an individual's sensory and } \\
\text { cognitive curiosity }\end{array}$ & [1], p. 673 \\
\hline $\begin{array}{l}\text { External } \\
\text { regulation }\end{array}$ & $\begin{array}{l}\text { External regulation occurs when } \\
\text { behavior is regulated by rewards or } \\
\text { in order to avoid negative } \\
\text { consequences }\end{array}$ & [23], p. 177 \\
\hline Attitude & $\begin{array}{l}\text { An individual's evaluation of the } \\
\text { behavior of interest }\end{array}$ & [5] p. 254 \\
\hline $\begin{array}{l}\text { Behavioral } \\
\text { intention }\end{array}$ & $\begin{array}{l}\text { A person's perceived likelihood or } \\
\text { subjective probability that he or she } \\
\text { will engage in a given behavior }\end{array}$ & [47] \\
\hline
\end{tabular}

\section{Methodology}

A quantitative survey was used to investigate the effects of the hypothesized relationships in the context of gamified workshops. The survey was designed to measure changes in attitudes and behavioral intention and the antecedents thereof.

\subsection{Sampling}

This study used gamified workshops to assess the effect of enjoyment, curiosity, and external regulations on attitudes and behavioral intentions, with the unit of analysis being SCM professionals in an apprenticeship. We identified the pool of potential respondents through desktop research into the leading SCM companies and educational institutions in Austria. In total, four vocational institutes that offer a part-time study program with a major in SCM for apprentices were identified and invited to participate in the study. All four institutes agreed to partake with at least one class of students who were in the second or third year. Thus, all the participants had at least one year of professional experience in the transport or supply chain sector. It was mandatory for the participants in the chosen classes to participate in the workshops. As far as experience and age is concerned, we strived to make the sample as homogeneous as possible in order to avoid any confounding impact of these variables.

\subsection{Measurement items}

We used existing scales from the literature to ensure the validity and the comparability of the results. All survey items were assessed with either semantic differentials or seven-point Likert scales ranging from 1 (strongly agree) to 7 (strongly disagree). In order to account for the specific topic of the workshop (i.e., sustainable transport) several minor wording modifications had to be made. Additionally, pretests were conducted with individuals from the target group to ensure the understandability of the questions and the parsimony of the scales. Following these pretests, several items were eliminated based on judgmental criteria ("scale purification"), but no ex post modifications of the scales were made [58].

Our semantic differential scale for enjoyment (i.e., joy) was based on the five-item scale for joy from [43], who themselves built on substantial previous work. [55], for example, proposed a threeitem scale and [54] used a semantic differential with four items. Our scale was designed to measure the level of enjoyment (dis)confirmation immediately after the workshop. In other words, the scale was intended to measure the (perceived) enjoyment of the gamified workshop. The three-item curiosity scale was also taken from [43], who adapted a scale by [1] to a gaming context. The external regulation scale stems from [23]. Based on the pretest, the original four items were reduced to two items which best convey the meaning of mandated use. The four-item attitude scale was taken without any modifications from [5] and the three items for measuring behavioral intention were taken from [53] with only slight modifications to match the context of this study. Table 2 summarizes the scales that were used in the gamified workshop and the respective sources.

Table 2. Measurement scales

\begin{tabular}{lll}
\hline Construct & Items & Source \\
\hline Enjoyment & All things considered, the workshop & [1] \\
& was \\
& (1) enjoyable .. unenjoyable \\
& (2) interesting . . tedious \\
& (3) arousing . . boring \\
& (4) fun ... not fun \\
(1) This experience excited my & C1] \\
& (2) This experience made my curious \\
(3) This experience aroused my & \\
External & Imagination \\
regulation & (1) ... because I was supposed to do it
\end{tabular}




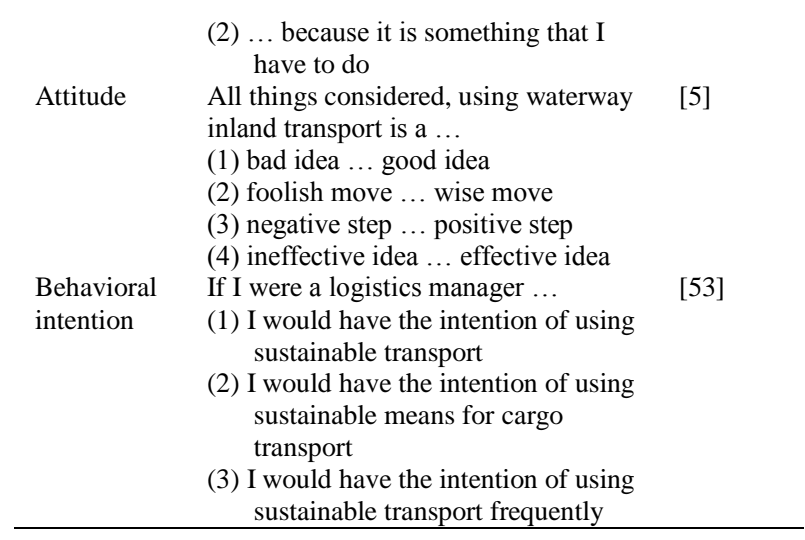

\subsection{Data collection and analysis}

Previous research on gamification can be categorized into behavioral and psychological outcomes [27]. In this study we investigate both outcomes using validated measurement instruments. The data collection took place between October 2015 and June 2016. In total, 261 SCM professionals participated in seven workshops that included identical gamification elements. For the purpose of this study, which was to investigate the effects of these gamified workshops on antecedents of attitudinal and behavioral change, primary data was gathered with questionnaires that were administered to the workshop participants immediately before and after their gamification experience. The data was collected completely anonymously in order to ensure the privacy of the participants and to avoid social desirability bias.

\subsection{Game elements in the workshops}

The workshops were organized as all-day events which took place at a major supply chain hub. The overall design of the workshops was standardized in order to minimize the confounding impact of the role of the workshop leader. They were designed in a competition format, whereby participants received points for correctly solving problems or work tasks. At the end of each workshop, the best team received a prize and a badge.

The main aim of the game elements in this study was to increase users' motivation to concentrate on a specific topic and to achieve a change in individuals' behavioral intentions [33]. The following game elements, which are based on [36], [52], [11], [24], [27] and [15], were used in the workshop:

- Clear goals: The participants knew exactly the aims of the overall workshop and each respective task. They also knew the maximum number of points for each task.

- Immediate oral feedback: The participants learned immediately if they had found the correct solution or what the correct solution would have been otherwise.

- Leaderboard: The participants knew exactly how their team and the other teams were performing.

- Time constraint: For some tasks the participants had only limited time available to find solutions.

- Challenge \& cooperation: The workshop was designed in the form of a competition; the teams received points for correct answers or good solutions. Participants needed to collaborate within the teams to be able to solve the tasks.

- Storytelling: The tasks were embedded in a story so the participants were motivated and got involved in this story.

- Rewards \& badges: The best team received a prize, a picture of the winners and a badge, which was sent after the workshop. Rewards were used to externally motivate the participants.

At the beginning of the gamified workshop, the participants were informed about the schedule, the rules of the planned competition and the privacy of their personal information. Teams were formed and the participants had to remain in those teams for the entire day-long workshop. Each team was rewarded with a specified number of points for each task it successfully completed. The best team, measured in terms of the highest points tally, received a prize.

The schedule for the gamified workshop included five tasks: the first task was an interactive lecture on sustainable SCM from an industry expert with a focus on transport logistics. During the lecture, participants had to answer questions within two minutes (time constraint) where each team received points for the correct answer(s) (competition). The second task was to solve a transport calculation, which was limited to 25 minutes (time constraint) for the calculation and five minutes for the feedback (immediate feedback, competition). Next, a simulation game was embedded in a story (storytelling) before participants had to make their transport and transshipment decisions in real time. The next task was a container quiz, where time was limited again (time constraint) and participants were rewarded with points for correct solutions. The last task was called "future transport ideas". Participants had limited time (time constraint) to find future transport ideas and tell their story (storytelling).

Participants received additional points for fast and correct solutions, and for explaining their solution to the other teams. The scoring system was identical for 
all gamified workshops and the participants were evaluated by the same people (researchers and representatives from the industry) in all workshops in order to ensure equal treatment.

\section{Results}

The data were analyzed with IBM SPSS Statistics 24 and IBM SPSS Amos 24.0.0. Apart from using descriptive statistics, we applied confirmatory factor analysis (CFA) and structural equation modeling (SEM), which are two of the most commonly used multivariate statistical methods in empirical research and are well accepted in the IS community. SEM is a method that is applied for the simultaneous testing of hypotheses which are based on theoretical models. Since the focus of this paper is on testing established models rather than theory development and our sample size exceeds the suggested threshold of 250 observations, we preferred a covariance-based over a variance-based (i.e., PLS) approach [50].

\subsection{Descriptive results}

In total 261 persons participated in the workshop and all of them filled out two surveys, which were administered immediately before and after the event (response rate: 100\%). For the SEM analysis only the latter were used. Out of the participants, 161 (61.7\%) were male and $100(38.3 \%)$ female. All of them were in an apprenticeship program in a logistics company and attended, in parallel, a vocational training. The age range was from 15 to 44 years with a mean value of 18.73 and a standard deviation of 4.15. All of them worked at different operational and managerial levels in SCM and logistics in their respective companies and most of them were at the beginning of their professional career.

\subsection{Measurement model assessment}

To examine the reliability and validity of the scales we used confirmatory factor analysis. The composite reliability (CR) and the average variance extracted (AVE) can be found in Table 3. The CR values for attitude, enjoyment, curiosity and behavioral intention ranged from 0.88 to .0 .93 , indicating a high level of convergent validity. Similarly, their AVE was well above the recommended threshold of 0.5 . In the case of external regulation, however, the standardized loading was larger than one and the error variance was negative, which resulted in a so-called Heywood case [14]. The results for er1 thus have no meaning. We therefore equated the factor loadings of the two indicators of this latent variable and the result was satisfactory (er2). However, the initial results indicated a severe problem with the external regulation scale and care should be taken when interpreting the impact of this scale.

Discriminant validity was assessed by comparing the correlations among constructs with the square root of the AVEs (as shown in bold as the diagonal of Table 3) and examining the cross-loadings among items and constructs. The square roots of the AVE exceeded the correlations and the rotated crossloadings were smaller than the factor loadings of each item, indicating sufficient discriminant validity. Common method bias (CMB), which was measured according to Harman's one factor approach, turned out not to be a major problem in this study.

Table 3. Reliability and validity measures

\begin{tabular}{|c|c|c|c|c|c|c|c|}
\hline & CR & AVE & att & enj & cur & bi & er \\
\hline att & 0.91 & 0.71 & 0.844 & & & & \\
\hline enj & 0.88 & 0.66 & 0.530 & 0.811 & & & \\
\hline cur & 0.91 & 0.76 & 0.557 & 0.662 & 0.873 & & \\
\hline bi & 0.93 & 0.81 & 0.718 & 0.481 & 0.559 & 0.897 & \\
\hline er1 & 12.7 & 19.3 & 0.009 & 0.019 & 0.015 & 0.018 & 4.395 \\
\hline er2 & .72 & .56 & 0.034 & -0.01 & -0.06 & 0.041 & 0.748 \\
\hline
\end{tabular}

\subsection{Structural model assessment}

The fit of the structural model was satisfactory $($ RMSEA $=.074 ;$ CFI $=.948 ;$ TLI $=.928)$ and the results lend partial support to our model. The two constructs enjoyment $(\beta=.29, \mathrm{p}<.001)$ and curiosity $(\beta=.39, \mathrm{p}<.001)$, which are closely related to the hedonic and motivational aspects of gamification, had a significant positive effect on attitude (see Figure 2). Even though student participation in the workshops was mandatory, the effect of external regulation was insignificant $(\beta=.06)$, which is in line with the measurement problems of the construct that we experienced. Additionally, the constructs enjoyment and curiosity were strongly correlated ( $r=$ $.66, \mathrm{p}<.001)$. The relationship between attitude and behavioral intention turned also out to be highly significant $(\beta=.73, \mathrm{p}<.001)$. With $\mathrm{R}^{2}$ values of $39 \%$ for attitude and $54 \%$ for behavioral intention, our model has a substantial amount of explanatory power. 


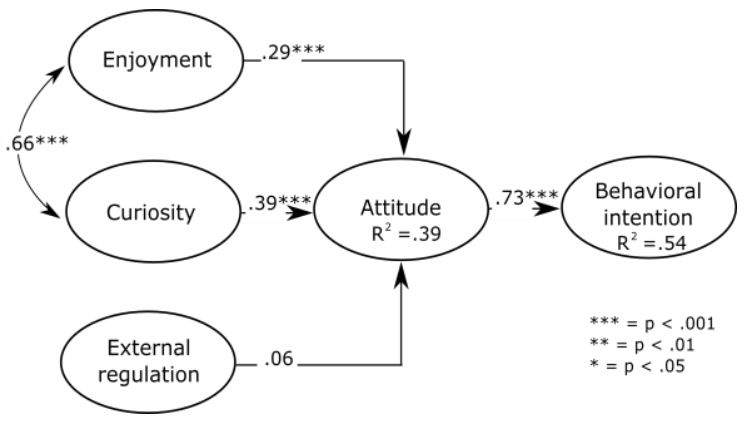

Figure 2. SEM results

\subsection{Impact of the workshops}

The results above highlight the important influence of various attitudinal and behavioral antecedents in a gamified workshop setting. In order to account for actual changes in attitude and behavior, we measured these constructs immediately before and after the workshop. Again, we used a 7point Likert scale with 1 indicating the highest level of agreement and 7 the lowest. It turned out that the attitude of the participants prior to the workshop was already fairly positive $(\mu=2.23, \sigma=1.09)$, but this value even increased immediately after the workshop $(\mu=2.05, \sigma=1.03)$. Since the data was not normally distributed, a non-parametric Wilcoxon signed-rank test was conducted and showed a statistically significant difference in students' attitude $(Z=-2.51$, $\mathrm{p}<.01)$. Similarly, the intention to use sustainable transport increased from a mean value of $3.15(\sigma=$ $1.43)$ to $2.45(\sigma=1.38)$. The Wilcoxon signed-rank test was also significant $(Z=-7.35, p<0.01)$.

\section{Discussion and implications}

In this study we hypothesized a positive impact of intrinsic factors, being measured with the previously validated constructs "enjoyment" and "curiosity", on individuals' attitude and behavioral intention to adopt sustainable business practices. Furthermore, we included the construct "external regulation" to account for mandatory participation in the gamified workshops. The empirical results from a study of 261 SCM professionals who are currently in an apprenticeship scheme and receive on-the-job training confirmed our hypotheses that enjoyment and curiosity contribute to a positive change in attitudes and subsequently also in behavioral intentions. The effect of "external regulation" on attitude turned out to be insignificant, which is remarkable since all participants had to attend the workshops as part of their training program. The high correlation between curiosity and enjoyment can be explained by the setting of workshops, in which a positive learning atmosphere was created and the intellectual capabilities of the participants were challenged.

\subsection{Theoretical implications}

The results of our study confirm the validity of the measurement scales with the single exception of the construct "external regulation". The slight modifications of the scales which we undertook were done ex ante and based on several rounds of pretesting. These modified scales provide new measurement tools for researchers who want to investigate phenomena in the context of sustainable SCM systems. Our parsimonious model can easily be extended to account for other constructs pertaining to extrinsic and intrinsic motivational factors.

As far as theory development is concerned, our study builds on previous attitudinal and behavioral research and applies it to the specific context of gamified information systems. It thus supports the theoretical underpinning of gamification studies.

\subsection{Managerial implications}

This study was conducted with (aspiring) SCM professionals, many of whom will take their place in management in the years to come. It is therefore crucial to know how their attitudes and behavioral intentions can be shaped in an early stage of their career. This study clearly had a normative aspect, since sustainable transport practices are superior to traditional transport systems when it comes to the overall environmental impact. Thus, it was interesting to see how gamification elements which were incorporated into the workshop design were able to positively impact participants' attitudes and intentions. Future workshop designers (as well as researchers) can benefit from our findings by designing workshops in ways which increase enjoyment and create curiosity. This can be done, as we have shown in this study, by including game elements such as clear goals, immediate feedback, leaderboards, time constraints, challenges \& cooperation, storytelling and rewards \& badges. Since gamification supports behavioral change, it can easily be incorporated into educational and training programs that promote sustainable business practices. 


\section{Limitations and future research}

Our model provides useful results regarding the importance of intrinsic motivating factors, which are triggered by gamified workshops. However, the initial results highlighted some problems with the measurement of "external regulations", which deserve further attention. A so-called Heywood case refers to a situation in which the communality for a measured variable accounted for by the common factor is estimated to be at 1 or even greater. Such a situation may indicate a misspecification of the model or violations of the assumptions of the common factor model [19]. Further research is needed in order to detect to what extent mandatory attendance has an impact on the perception and success of gamified workshops.

The data sets which we present in this paper were collected immediately before and after the workshop, with the SEM model using the latter and the scales referring to individuals' perceptions of the game elements. A more elaborate experimental design with different control groups would help to shed light on the impact and the durability of attitudinal and behavioral changes. Furthermore, although we tried to standardize the design of the workshops as much as possible, the role of the instructor also deserves further attention.

Finally, we acknowledge that, in addition to enjoyment and curiosity, individuals can also have additional antecedents of behavioral change and the results might differ for participants from different age groups and with varying levels of professional expertise. Future research should therefore include and test further constructs, many of which can be found in the existing literature. The scope of this study was limited to the application of gamification to trigger attitudinal and behavioral changes in the sustainable transport industry, which in turn will lead to more environmentally friendly business practices, and we hope that other researchers will replicate the findings of our study in different industries. This will not only foster the application of gamification to create change, but also support the transfer of research results into practice.

\section{References}

[1] Agarwal, R. and E. Karahanna, "Time flies when you're having fun: cognitive absorption and beliefs about information technology usage", MIS Quarterly, 24(4), 2000, pp. 665-694.

[2] Ajzen, I., "The theory of planned behavior", Organizational Behavior and Human Decision Processes, 50(2), 1991, pp. 179-211.

[3] Bateman, C., "The aesthetic motives of play", in Emotion in Games: Theory and Praxis, K. Karpouzis and G.N. Yannakakis, Editors. 2016. Springer: Cham.

[4] Berlyne, D.E., "A theory of human curiosity", British Journal of Psychology, 45(3), 1954, pp. 180-191.

[5] Bhattacherjee, A. and G. Premkumar, "Understanding changes in belief and attitude toward information technology usage: a theoretical model and longitudinal test", MIS Quarterly, 28(2), 2004, pp. 229-254.

[6] Blohm, I. and J.M. Leimeister, "Gamification design of IT-based enhancing services for motivational support and behavioral change", Business \& Information Systems Engineering, 5(4), 2013, pp. 275-278.

[7] Brown, S.A., A.P. Massey, M.M. Montoya-Weiss, and J.R. Burkman, "Do I really have to? User acceptance of mandated technology", European Journal of Information Systems, 11(4), 2002, pp. 283-295.

[8] Chen, Y., S. Shi, and W.S. Chow, "Investigating users' extrinsic motivation for green personal computing", Journal of Computer Information Systems, 56(1), 2016, pp. 70-78.

[9] Csikszentmihalyi, M., Beyond boredom and anxiety, Jossey-Bass, San Francisco, 1975.

[10] Csikszentmihalyi, M., Flow and the psychology of discovery and invention, Harper Collins, New York, 1996.

[11] Dahlinger, A. and F. Wortmann, "Towards the design of eco-driving feedback information systems-a literature review", Multikonferenz Wirtschaftsinformatik (MKWI), 2016, pp. 801-812.

[12] Davis, F.D., R.P. Bagozzi, and P.R. Warshaw, "User acceptance of computer technology: a comparison of two theoretical models", Management Science, 35(8), 1989, pp. 982-1003.

[13] Davis, F.D., R.P. Bagozzi, and P.R. Warshaw, "Extrinsic and intrinsic motivation to use computers in the workplace", Journal of Applied Social Psychology, 22(14), 1992, pp. 1111-1132.

[14] de Winter, J.C.F., D. Dodou, and P.A. Wieringa, "Exploratory factor analysis with small sample sizes", Multivariate Behavioral Research, 44(2), 2009, pp. 147181.

[15] Deterding, S., D. Dixon, R. Khaled, and L. Nacke, "From game design elements to gamefulness: defining gamification", in Proceedings of the 15th International Academic MindTrek Conference: Envisioning Future 
Media Environments, A. Lugmayr, Editor, pp. 9-15, New York. 2011.

[16] Dias, J., "Teaching operations research to undergraduate management students: the role of gamification", International Journal of Management Education (Elsevier Science), 15(1), 2017, pp. 98-111.

[17] Directorate-General for Internal Policies, The future of sustainable freight transport and logistics, European Parliament, Brussels, 2010.

[18] Elkington, J., Cannibals with forks: the triple bottom line of 21st century business, Capstone, Oxford, 2002.

[19] Fabrigar, L.R., D.T. Wegener, R.C. MacCallum, and E.J. Strahan, "Evaluating the use of exploratory factor analysis in psychological research", Psychological Methods, 4(3), 1999, pp. 272-299.

[20] Fishbein, M. and I. Ajzen, Belief, attitude, intention and behavior: an introduction to theory and research, Addison-Wesley Pub. Co., Reading, Mass. Don Mills, Ontario, 1975.

[21] Ghazizadeh, M., J.D. Lee, and L.N. Boyle, "Extending the technology acceptance model to assess automation", Cognition, Technology \& Work, 14(1), 2012, pp. 39-49.

[22] Gholami, R., R.T. Watson, A. Molla, H. Hasan, and N. Bjørn-Andersen, "Information systems solutions for environmental sustainability: how can we do more?", Journal of the Association for Information Systems, 17(8), 2016, pp. 521-536.

[23] Guay, F., R.J. Vallerand, and C. Blanchard, "On the assessment of situational intrinsic and extrinsic motivation: the situational motivation scale (SIMS)", Motivation and Emotion, 24(3), 2000, pp. 175-213.

[24] Hamari, J., "Do badges increase user activity? A field experiment on the effects of gamification", Computers in Human Behavior, 1(71), 2017, pp. 469-478.

[25] Hamari, J. and L. Keronen, "Why do people play games? A meta-analysis", International Journal of Information Management, 37(3), 2017, pp. 125-141.

[26] Hamari, J. and J. Koivisto, "Why do people use gamification services?", International Journal of Information Management, 35(4), 2015, pp. 419-431.

[27] Hamari, J., J. Koivisto, and H. Sarsa, "Does Gamification Work? A literature review of empirical studies on gamification", in Proceedings of 47th Hawaii International Conference on System Sciences (HICSS), IEEE, Editor, pp. 3025-3034, Waikoloa. 2014.

[28] Han, L., "Green button program: an analysis of business opportunities", Michigan: Erb Institute for Global Sustainable Enterprise, 2012.

[29] Hart, S.L., "Beyond greening: strategies for a sustainable world", Harvard Business Review, 75(1), 1997, pp. 66-76.

[30] Hsu, C.-L., Y.-C. Chen, T.-N. Yang, and W.-K. Lin, "Do website features matter in an online gamification context? Focusing on the mediating roles of user experience and attitude", Telematics and Informatics, 34(4), 2017, pp. 196-205.

[31] Huizinga, J., Homo ludens: a study of the play element in culture, Beacon Press, Boston, 1967.

[32] Hung, S.-Y., J.C.-A. Tsai, and S.-T. Chou, "Decomposing perceived playfulness: a contextual examination of two social networking sites", Information \& Management, 53(6), 2016, pp. 698-716.

[33] Huotari, K. and J. Hamari, "A definition for gamification: anchoring gamification in the service marketing literature", Electronic Markets, 27(1), 2017, pp. 17-22.

[34] Intergovernmental Panel on Climate Change, Climate Change 2014: Mitigation of Climate Change: Working Group III Contribution to the IPCC Fifth Assessment Report, Cambridge University Press, Cambridge, 2015.

[35] Isikman, E., D.J. MacInnis, G. Ülkümen, and L.A. Cavanaugh, "The effects of curiosity-evoking events on activity enjoyment", Journal of Experimental Psychology: Applied, 22(3), 2016, pp. 319-330.

[36] Kapp, K.M., The gamification of learning and instruction: game-based methods and strategies for training and education, Pfeiffer, San Francisco, 2012.

[37] Kashdan, T.B., P. Rose, and F.D. Fincham, "Curiosity and exploration: facilitating positive subjective experiences and personal growth opportunities", Journal of Personality Assessment, 82(3), 2004, pp. 291-305.

[38] Lee, D.Y. and H. Ryu, "Learner acceptance of a multimedia-based learning system", International Journal of Human-Computer Interaction, 29(6), 2013, pp. 419-437.

[39] Lee, J.J., E. Matamoros, R. Kern, J. Marks, C. de Luna, and W. Jordan-Cooley, "Greenify: fostering sustainable communities via gamification", in CHI '13 Extended Abstracts on Human Factors in Computing Systems, W.E. Mackay, Editor, pp. 1497-1502, Paris. 2013.

[40] Li, Y., C.-H. Tan, H. Xu, and H.-H. Teo, "Open source software adoption: motivations of adopters and amotivations of non-adopters", ACM SIGMIS Database, 42(2), 2011, pp. 76-94.

[41] Liu, D., X. Li, and R. Santhanam, "Digital games and beyond: what happens when players compete", MIS Quarterly, 37(1), 2013, pp. 111-124.

[42] Liu, D., R. Santhanam, and J. Webster, "Towards meaningful engagement: a framework for design and research of gamified information systems", MIS Quarterly, accepted 11. November 2016, forthcoming.

[43] Lowry, P.B., J. Gaskin, N. Twyman, B. Hammer, and T. Roberts, "Taking 'fun and games' seriously: proposing the hedonic-motivation system adoption model (HMSAM)", Journal of the Association for Information Systems, 14(11), 2012, pp. 617-671. 
[44] Malone, T.W., "Toward a theory of intrinsically motivating instruction", Cognitive Science, 5(4), 1981, pp. 333-369.

[45] Müller-Stewens, J., T. Schlager, G. Häubl, and A. Herrmann, "Gamified information presentation and consumer adoption of product innovations", Journal of Marketing, 81(2), 2017, pp. 8-24.

[46] Nah, F.F.-H., B. Eschenbrenner, and D. DeWester, "Enhancing brand equity through flow and telepresence: a comparison of 2D and 3D virtual worlds", MIS Quarterly, 35(3), 2011, pp. 731-747.

[47] National Library of Medicine, "Behavioral intention", National Academy Press,

https://chirr.nlm.nih.gov/behavioral-intention.php, accessed on 25. August 2017, Rockville Pike, Bethesda, 2017.

[48] OECD/ITF, ITF Transport Outlook 2015, OECD Publishing/ITF, Paris, 2015.

[49] Olsson, M., J. Högberg, E. Wästlund, and A. Gustafsson, "In-store gamification: testing a location-based treasure hunt app in a real retailing environment", 49th Hawaii International Conference on System Sciences (HICSS), IEEE, 2016, pp. 1634-1641.

[50] Reinartz, W., M. Haenlein, and J. Henseler, "An empirical comparison of the efficacy of covariance-based and variance-based SEM", International Journal of Research in Marketing, 26(4), 2009, pp. 332-344.

[51] Salvioni, D.M., F. Gennari, and L. Bosetti, "Sustainability and convergence: the future of corporate governance systems?", Sustainability, 8(11), 2016, pp. 125 .

[52] Star, K., Gamification, interdependence, and the moderating effect of personality on performance, Doctoral Thesis. University of Coventry, 2016.

[53] Taylor, S. and P.A. Todd, "Understanding information technology usage: a test of competing models", Information Systems Research, 6(2), 1995, pp. 144-176.

[54] van der Heijden, H., "User acceptance of hedonic information systems", MIS Quarterly, 28(4), 2004, pp. 695-704.

[55] Venkatesh, V., "Determinants of perceived ease of use: integrating control, intrinsic motivation, and emotion into the technology acceptance model", Information Systems Research, 11(4), 2000, pp. 342-365.

[56] Venkatesh, V. and F.D. Davis, "A theoretical extension of the technology acceptance model: four longitudinal field studies", Management Science, 46(2), 2000, pp. 186-204.

[57] Vesa, M., J. Hamari, Harviainen, J. Tuomas, and H. Warmelink, "Computer games and organization studies", Organization Studies, 38(2), 2016, pp. 273-284.

[58] Wieland, A., C.F. Durach, J. Kembro, and H. Treiblmaier, "Statistical and judgmental criteria for scale purification", Supply Chain Management: An International Journal, 22(4), 2017, pp. 321-328.

[59] Wood, L.C. and T. Reiners, "Gamification in logistics and supply chain education: extending active learning", in Proceedings of the International Conference on Internet Technologies \& Society, P. Kommers, T. Issa, and P. Isaías, Editors, pp. 101-106, Perth. 2012.

[60] Wu, Z. and M. Pagell, "Balancing priorities: decisionmaking in sustainable supply chain management", Journal of Operations Management, 29(6), 2011, pp. 577-590. 